\title{
REMOTE SENSING OF ANTARCTIC SEA ICE WITH COORDINATED AIRCRAFT AND SATELLITE DATA ACQUISITIONS
}

\author{
Son V.Nghiem ${ }^{1}$, Thomas Busche ${ }^{2}$, Thomas Kraus ${ }^{2}$, Markus Bachmann $^{2}$, Nathan Kurtz ${ }^{3}$, John Sonntag ${ }^{3}$, \\ John Woods ${ }^{3}$, Stephen Ackley ${ }^{4}$, Hongjie Xie $^{4}$, Ted Maksym ${ }^{5}$, Kirsteen Tinto ${ }^{6}$, Wolfgang Rack ${ }^{7}$, \\ Pat Langhorne $^{8}$, Christian Haas ${ }^{9,10}$, Caryn Panowicz ${ }^{11}$, Ignatius Rigor ${ }^{12}$, \\ Paul Morin ${ }^{13}$, Lisa Nguyen ${ }^{1}$, and Gregory Neumann ${ }^{1}$ \\ ${ }^{1}$ Jet Propulsion Laboratory, California Institute of Technology, Pasadena, California, USA \\ ${ }^{2}$ German Aerospace Center, Microwaves and Radar Institute, Oberpfaffenhofen, Germany \\ ${ }^{3}$ NASA Goddard Space Flight Center, Greenbelt, Maryland, USA \\ ${ }^{4}$ Department of Geological Sciences, University of Texas at San Antonio, Texas USA \\ ${ }^{5}$ Woods Hole Oceanographic Institution, Woods Hole, Massachusetts, USA \\ ${ }^{6}$ Lamont-Doherty Earth Observatory, Columbia University, Palisades, New York, USA \\ ${ }^{7}$ Gateway Antarctica, University of Canterbury, Christchurch, New Zealand \\ ${ }^{8}$ Department of Physics, University of Otago, Dunedin, New Zealand \\ ${ }^{9}$ York University, Toronto, Canada and ${ }^{10}$ Alfred Wegener Institute, Bremerhaven, Germany \\ ${ }^{11}$ U.S. National Ice Center, Washington, District of Columbia, USA \\ ${ }^{12}$ Polar Science Center, University of Washington, Seattle, Washington, USA \\ ${ }^{13}$ Polar Geospatial Center, University of Minnesota, Saint Paul, Minnesota, USA
}

\begin{abstract}
Remote sensing of Antarctic sea ice is required to characterize properties of the vast sea ice cover to understand its long-term increase in contrast to the decrease of Arctic sea ice. For this objective, the OIB/TanDEM-X Coordinated Science Campaign (OTASC) was successfully conducted in 2017 to obtain contemporaneous and collocated remote sensing data from NASA's Operation IceBridge (OIB) and the German Aerospace Center (DLR) TanDEM-X Synthetic Aperture Radar (SAR) system at X band together with Sentinel-1 and RADARSAT-2 SARs at $\mathrm{C}$ band in conjunction with WorldView satellite spectral sensors, surface measurements, and field observations. The Weddell Sea and the Ross Sea were two primary regions while SAR data were also collected over six other regions in the Southern Ocean. Satellite SAR data included both polarimetric and interferometric capabilities to infer snow and sea ice information in three dimensions (3D), while OIB/P-3 aircraft data include snow radar together with altimeter data for snow and sea ice observations in 3D over the Weddell Sea. Across the Ross Sea, IcePOD and AntNZ/York-University flights were carried out together with satellite SAR data acquisitions.
\end{abstract}

Index Terms - Antarctic sea ice, SAR, TanDEM-X, Sentinel-1, RADARSAT-2, OIB, IcePOD, WorldView

\section{INTRODUCTION}

The polar sea ice conundrum regarding the contrast between Antarctic sea ice increase versus Arctic sea decrease in a multi-decadal time scale is a major cryospheric science issue to be resolved. This is considered by scientists as the polar sea ice paradox [1-4]. While a number of explanations have been suggested [5-12], it remains necessary to answer simultaneously and self-consistently to all of these science questions about Antarctic sea ice including: Effective processes for Antarctic sea ice production, factors protecting the sea ice cover, mechanisms sustaining sea ice, processes causing regional variability, and causes of opposite effects in Antarctic and Arctic sea ice while both have to obey the same physics without any discord among different factors [13]. To provide quantitative observations of Antarctic sea ice in order to answer the science questions, we developed and successfully carried out OTASC with the participation of multiple agencies and institutions.

\section{OTASC FIELD CAMPAIGN}

The OTASC field campaign was developed to conduct multiple field surveys to obtain contemporaneous and collocated NASA's Operation IceBridge (OIB) and the German Aerospace Center (DLR) TanDEM-X data [13] in conjunction with surface measurements using buoys, 


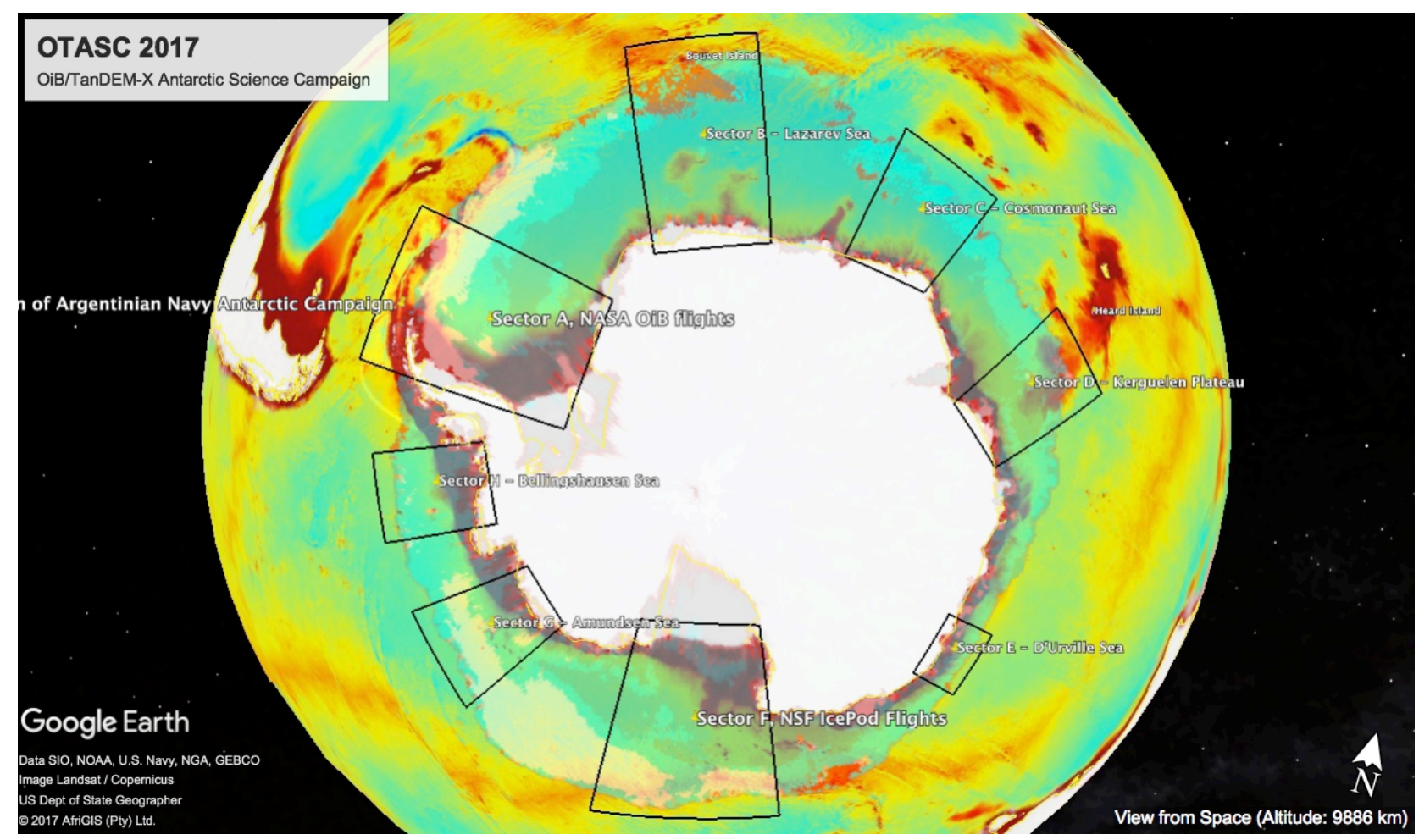

Figure 1. OTASC coverage over 8 sectors (black polygons) around Antarctica including Sector A for Weddell Sea, Sector B for Lazarev Sea including Bouvet Island, Sector C for Cosmonaut Sea, Sector D for the region around Kerguelen Plateau, Sector E for D’Urville Sea, Sector F for Ross Sea, Sector G for Amundsen Sea, and Sector H for Bellingshausen Sea.

stations, and field observations from Antarctic icebreaker expeditions and drone operations. OIB Airborne Topographic Mapper (ATM) data can be used to calibrate Digital Mapping System (DMS) digital elevation model (DEM), and compared to correctly interpret TanDEM-X synthetic aperture radar (SAR) data in two (2D) and three dimensions (3D). While OIB can provide accurate and high-resolution measurements, the aircraft data are limited to a finite number of flight lines with point-wise or narrowstrip measurements. Once verified with OIB results, TanDEM-X can provide multiple measurements of sea ice properties across the vast expanse of Antarctic sea ice around its maximum extent. This may take more than a month to complete such a massive data acquisition. DLR approved and tasked the satellite to acquire TanDEM-X SAR data, and NASA flew a P-3 aircraft to obtain a full suite of OIB data over sea ice as included in the Fall 2017 IceBridge P-3 flight plans [14].

Moreover, in collaboration with the University of Texas at San Antonio led project Polynyas and Ice Production in the Ross Sea (PIPERS) supported by the National Science Foundation (NSF), additional field campaign was coordinated with OTASC to fly the IcePOD aircraft carrying a suite of instrument similar to OIB. In addition, a Basler aircraft carrying an EM Bird instrument was used to measure ice thickness [15]. Ocean and ice buoys were deployed and surface expeditions for field observations were launched together with assistance from the U.S.
National Ice Center for operational forecast and imagery products to support OTASC. In coordination with the Polar Geospatial Center of the University of Minnesota, WorldView data collections were tasked and obtained along OTASC aircraft and satellite ground tracks in the Weddell Sea and the Ross Sea. OTASC involved the participation and collaboration by 17 institutions and agencies from five countries.

\section{SATELLITE REMOTE SENSING DATA}

The X-band TanDEM-X SAR system included monostatic, bistatic, polarimetric, and single-pass interferometric capabilities for robust ice and open water identification, sea ice classification, ice drift measurement, and 3D DEM assessment at a high resolution. Because radar backscatter is sensitive to sea ice roughness that correlates with sea ice thickness [16], TanDEM-X 2D SAR backscatter patterns are an independent source of information to cross-verify 3D DEM results from other remote sensing estimates. SAR backscatter can be used to examine the spatial distribution of roughness and thickness of Antarctic sea ice in the lateral two dimensions (2D). Since DEMs derived from SAR interferometry are relative to scattering center height, which is dependent on the penetration depth in snow-covered sea ice as a function of the electromagnetic wave frequency, a DEM of the snow surface from coordinated OIB 3D data is necessary to understand and interpret TanDEM-X 3D 


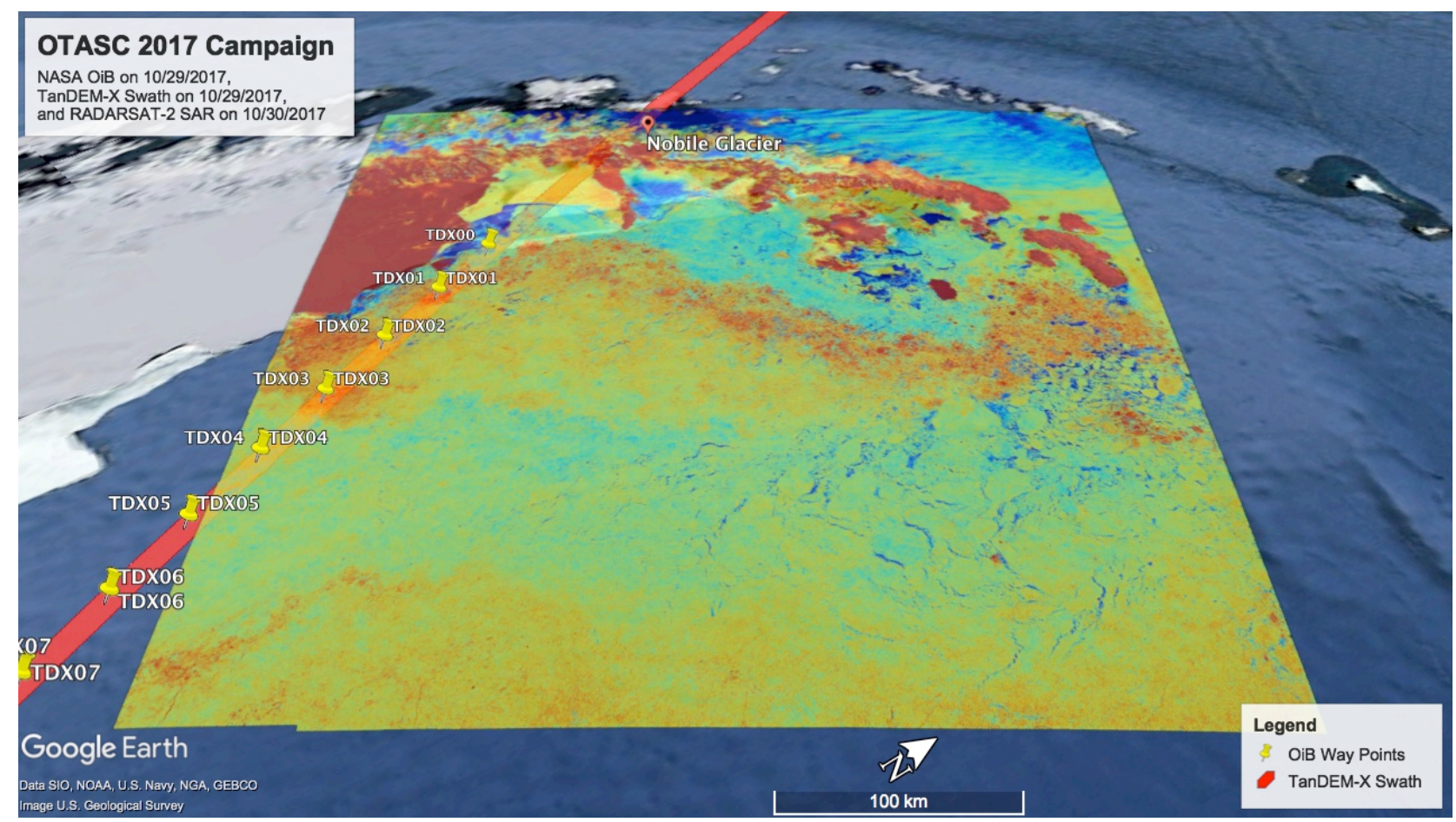

Figure 2. A segment of OTASC OIB/P-3 flight (waypoints marked by yellow pins) coordinated along TanDEM-X ground swath (red strip) on 29 October 2017 together with RADARSAT-2 SAR on 30 October 2017. The full OIB/TanDEM-X coverage during this flight was extensive $(\sim 1000 \mathrm{~km})$.

observations over different sea ice classes that can be mapped in $2 \mathrm{D}$ by TanDEM-X data. Sentinel- 1 and RADARSAT-2 provided more SAR data at $\mathrm{C}$ band to be analyzed together with the X-band data. From WorldView, the spectral data had an excellent resolution of 1 meter.

\section{AIRCRAFT REMOTE SENSING DATA}

Measurements from the OIB can provide relevant data to characterize Antarctic sea ice with snow cover. The OIB is a NASA mission using aircraft to survey the Earth's polar ice to obtain three-dimensional view of Arctic and Antarctic ice sheets, ice shelves, and sea ice [17]. ATM measurements include surface elevation, slope, and roughness [18] with a swath width of $\sim 250 \mathrm{~m}$ and a footprint size of $1 \mathrm{~m}$ on the surface along the flight track. DMS data could be processed to obtain geolocated and orthorectified images representing DEM with a relative accuracy of $\sim 0.2 \mathrm{~m}$ and a resolution of $10 \mathrm{~cm} \times 10 \mathrm{~cm}$ [19] over a swath width of several hundred meters depending on the flight altitude. Within the DMS DEM accuracy limit, areas with pronounced features on sea ice surface such as deformed sea ice, ruble ice, pressure ridges, and other largescale roughness can be identified and statistically categorized over various sea ice classes. OIB snow radar provided the capability to measure snow depth on sea ice, needed to estimate sea ice thickness from freeboard measurements. IcePOD aircraft flown over the Ross Sea gave the suite of remote sensing data similar to OIB data.

\section{OTASC COVERAGE}

To quantify the properties of Antarctic sea ice in detail and to determine its change demand extensive observations from the surface to aircraft and satellite levels at multiple scales in time and in space across the vast extent of the Southern Ocean. This is particularly important to advance Antarctic science research, as there have been overwhelmingly more observations and modeling activities for the Arctic. Our approach is to maximize the science return from NASA's significant investment in the current OIB by developing a collaborative coordination with the collection of a massive satellite SAR dataset from TanDEM-X acquired over the Antarctic sea ice cover around its seasonal maximum extent, typically reached in September-October during the austral spring transition.

To capture differences in sea ice characteristics and processes in different regions of the Southern Ocean, OTASC covered eight sectors (Figure 1) including Sector A for Weddell Sea, Sector B for Lazarev Sea including Bouvet Island, Sector $\mathrm{C}$ for Cosmonaut Sea, Sector D for the region of Kerguelen Plateau, Sector E for D'Urville Sea, Sector F for Ross Sea, Sector G for Amundsen Sea, and Sector H for Bellingshausen Sea.

The OIB/P-3 aircraft flight for OTASC on 29 October 2017 (Figure 2) followed the southern leg of the baseline priority Seelye Loop mission (though about $300 \mathrm{~km}$ south of the nominal line), a mission flown almost every year of OIB. It targeted gradients in sea ice freeboard and thickness 
along the gate from the tip of the Antarctic Peninsula toward Cape Norvegia on Queen Maud Land coast. All instruments ran well during the flight across the Weddell Sea. Both ATM and DMS were impacted by clouds and altitude changes but otherwise performed well during the clear sections .

Another OIB/P-3 flight on 22 November 2017 was conducted to improve spatial coverage of sea ice conditions in the west-central Weddell Sea, and also to gain additional nearly synchronous data collection in coordination with TanDEM-X SAR acquisition. The western half of the Weddell Sea was almost entirely clear, with only a few cirrus clouds extending into the area from a storm system to the east. Excellent conditions were experienced throughout the flight, with just a few dozen miles of wispy fog near the south end that had little effect on the instruments. Science instrument mostly performed well with successful data collection over the entire line was nearly $100 \%$. Each of the OIB/P-3 flights over the Weddell Sea was very extensive and spanned a distance of $\sim 1000 \mathrm{~km}$. Initial TanDEM-X SAR data revealed high backscatter over the frontal ice zone in the Weddell Sea, corresponding to older, rougher, and thicker ice, while lower backscatter was observed in internal sea ice pack associated with younger, smoother, and thinner ice. OIB data are being processed to be used with SAR data to assess sea ice thickness. Multiple PIPERS/IcePOD flights over the Ross Sea were also successful in coordination with TanDEM-X data acquisition and surface fieldwork.

\section{ACKNOWLEDGMENTS}

The research carried out at the Jet Propulsion Laboratory, California Institute of Technology, was supported by the NASA Cryospheric Sciences Program. The TanDEM-X project is partly funded by the German Federal Ministry of Economics and Technology (Foerderkennzeichen $50 \mathrm{EE}$ 0601). The PIPERS/IcePOD research was funded by NSF.

\section{REFERENCES}

[1] J. E. Walsh, "A comparison of Arctic and Antarctic climate change, present and future," Antarctic Science, vol. 21, pp. 179188, doi:10.1017/S0954102009001874, 2009.

[2] J. P. Liu and J. A. Curry, "Resolving the Paradox of Antarctic Sea-Ice Growth," Bull. Amer. Meteorolog. Soc., vol. 92, pp. 1411$1412,2011$.

[3] T. Maksym, S. E. Stammerjohn, S. Ackley, and R. Massom, “Antarctic Sea Ice-A Polar Opposite?” Oceanography, vol. 25, pp. 140-151, 2012.

[4] J. King, "A resolution of the Antarctic paradox," Nature, vol. 505, pp. 491-492, 2014.

[5] G. J. Marshall, "Trends in the southern annular mode from observations and reanalyses," J. Clim., vol. 16, pp.4134-4143, 2003.
[6] S.-W. Son, et al. (2010). Impact of stratospheric ozone on Southern Hemisphere circulation change: A multimodel assessment," J. Geophys. Res., vol. 115, 2010.

[7] M. Sigmond and J. C. Fyfe, "Has the ozone hole contributed to increased Antarctic sea ice extent?" Geophys. Res. Lett., vol. 37, doi:10.1029/ 2010GL044301, 2010

[8] S. Manabe, R. J. Stouffer, M. J. Spelman, and K. Bryan, "Transient responses of a coupled ocean-atmosphere model to gradual change of atmospheric $\mathrm{CO}_{2}$. Part $\mathrm{I}$ : An- nual Mean Response," J. Clim., vol. 4, pp. 785-818, doi: 10.1175/15200442(1991)004<0785:TROACO>2.0.CO;2, 1991.

[9] J. Zhang, "Increasing Antarctic sea ice under warming atmospheric and oceanic conditions," J. Clim., vol. 20, pp. 25152529, doi: 10.1175/JCLI4136.1, 2007

[10] P. R. Holland, "The seasonality of Antarctic sea ice trends," Geophys. Res. Lett., vol. 41, pp. 4230-4237., doi: 10.1002/ 2014GL060172, 2014.

[11] J. Zhang, "Modeling the impact of wind intensification on Antarctic sea ice volume," J. Clim., vol. 27, pp. 202-214, doi:10.1175/JCLI-D-12-00139.1, 2014.

[12] S. V. Nghiem, I. G. Rigor, P. Clemente-Colón, G. Neumann, and P. P. Li, "Geophysical constraints on the Antarctic sea ice cover," Remote Sens. Environ., vol. 181, pp. 281-292, doi: 10.1016/j.rse.2016.04.005, 2016.

[13] S. V. Nghiem, G. Neumann, D. T. Nguyen, A. Moreira, and I. Hajnsek, "The Antarctic Circumpolar Frontal Ice Zone," Proc. Bionature, 16-21, ISBN: 978-1-61208-561-6, 2017

[14] J. Sonntag, Fall 2017 IceBridge P-3 Flight Plans, available for downloading from https://icebridge.gsfc.nasa.gov/? page_id=1772, accessed Aug. 2017

[15] C. Haas, S. Hendricks, H. Eicken, and A. Herber, "Synoptic airborne thickness surveys reveal state of Arctic sea ice cover," Geophys. Res. Lett., vol. 37, doi:10.1029/2010GL042652, 2010.

[16] T. Toyota, R. Massom, K. Tateyama, T. Tamura, and A. Fraser, "Properties of snow overlying the sea ice off East Antarctica in late winter, 2007," Deep Sea Research, Part II, vol. 58, pp. 1137-1148, doi:10.1016/j.dsr2. 2010.12.002, 2011.

[17] NASA, IceBridge Mission Overview. Available online from: https://www.nasa.gov/mission_pages/icebridge/mission/index.html accessed Feb. 2017.

[18] W. B. Krabill. IceBridge ATM L2 Icessn Elevation, Slope, and Roughness, Vers. 2, Boulder, CO, USA: NASA DAAC at the National Snow and Ice Data Center, updated 2016, doi:10.5067/CPRXXK3F39RV, accessed Feb. 2017.

[19] R. Dominguez. IceBridge DMS L1B Geolocated and Orthorectified Images, Vers. 1, Boulder, CO, USA: NASA DAAC at the National Snow and Ice Data Center, updated 2016, doi:10.5067/OZ6VNOPMPRJ0, accessed Feb. 2017. 